\title{
Human dendritic cells transfected with a human papilloma virus-18 construct display decreased mobility and upregulated cytokine production
}

\author{
SVETLANA F. KHAIBOULLINA ${ }^{1,5}$, SERGEY P. MORZUNOV ${ }^{2}$, MARK R. HALL ${ }^{2}$, \\ KENNY L. DE MEIRLEIR ${ }^{3}$, ALBERT A. RIZVANOV ${ }^{4}$ and VINCENT C. LOMBARDI ${ }^{1,5}$
}

\author{
${ }^{1}$ Department of Biochemistry and Molecular Biology, University of Nevada; ${ }^{2}$ Department of Microbiology, \\ University of Nevada School of Medicine, Reno, NV 89557, USA; ${ }^{3}$ Human Physiology, Vrije Universiteit Brussel, \\ Brussels, Belgium; ${ }^{4}$ Department of Genetics, Institute of Fundamental Medicine and Biology, Kazan \\ (Volga Region) Federal University, Kazan, Russia; ${ }^{5}$ Whittemore Peterson, Inst. Reno, Reno, NV, USA
}

Received June 4, 2013; Accepted July 12, 2013

DOI: 10.3892/ijo.2013.2074

\begin{abstract}
The marked depletion of dendritic cells (DCs) in skin cancers, as well as preneoplastic and neoplastic cervical epithelium, suggests a central role for DCs in productive human papillomavirus (HPV) infection and cancer promotion. It has been suggested that HPV may facilitate tumor development by reducing DC density, contributing to a decrease in local immune surveillance. In this study, we have examined the response of human DCs transfected with a construct containing the HPV18 genome and their subsequent expression of papilloma virus proteins. Transfected cells expressed the L1 major capsid protein and upregulated E6 and E7 oncoprotein transcripts as detected by RT-PCR. Transfection of DCs also resulted in a significant increase in cytokine production. Finally, we observed that HPV18 transfection decreased the migratory activity of DCs. Our data indicate that HPV transfection of DCs leads to changes in migratory activity and cytokine production, which potentially can suppress or delay immune responses to viral antigens. Additionally, changes in cytokine production by HPV-transformed human fibroblasts and human cervical epithelial cells revealed that the migratory and antigen-presenting functions of DCs may be impaired by the suppressive effects of cytokines produced by HPV-infected epithelial and stromal cells.
\end{abstract}

\section{Introduction}

The immunological mechanisms controlling human papillomavirus (HPV) infection are poorly understood. Initial

Correspondence to: Dr Vincent C. Lombardi, Department of Biochemistry and Molecular Biology, University of Nevada, $1664 \mathrm{~N}$ Virginia St. MS 0552, NV 89557, USA

E-mail: vlombardi@medicine.nevada.edu

Key words: papillomavirus, cytokine, dendritic cell, mobility infection of basal keratinocytes does not appear to activate a local immune response and HPV-associated skin lesions can persist for months or even years in immunocompetent subjects (1). Successful viral evasion from immune controlling mechanisms is likely the result of a number of factors including the low level of viral protein expression, nuclear localization of viral proteins in the basal layer of infected epithelium and/or the absence of cytolysis or cytopathic death resulting from viral replication and assembly (2). Accordingly, there is little or no release of the proinflammatory cytokines necessary for activation and migration of antigen-presenting cells. In addition, because HPV does not undergo a systemic or viremic phase of infection, the opportunities for immune cells to capture virus and present viral antigens in the lymph nodes are limited (3).

Previous studies have described a localized immune dysfunction accompanying cervical HPV infection. This dysfunction is characterized by quantitative and qualitative alterations of $\mathrm{CD}^{+} \mathrm{T}$ lymphocytes in the area of infection. $(4,5)$ In addition, it has been shown that the number and distribution of Langerhans cells (LCs) are abnormal in HPV-infected preneoplastic and neoplastic cervical epithelium (6-10). LCs are included in the lineage of immature dendritic cells (DCs) (11) and are considered to be the most important professional antigen-presenting cells in the mucosal immune system $(12,13)$.

Several paradigms have been proposed to explain LC depletion in the area of an HPV infection. For example, LC depletion might result from the creation of a locally unfavorable environment fostered by infected epithelial cells and fibroblasts. HPV-infected keratinocytes are known to express low levels of major histocompatibility complex restriction elements and do not present the necessary levels of costimulatory molecules for naive T-cell priming (14). Additionally, production of granulocyte-macrophage colony stimulating factor (GM-CSF) (15) as well as type I interferon $(16,17)$ is significantly decreased in HPV-infected keratinocytes. Such an immunosuppressive environment might lead to a decrease in intraepithelial DC maturation and prevent migration of DCs 
and macrophages to infected tissue. In addition, HPV may be capable of non-productively infecting DCs and producing a direct cytotoxic effect $(7,9)$. Several lines of indirect evidence support this possibility. For example, DCs are located in the basal and middle third of the squamous epithelium and commonly project numerous cytoplasmic processes into more superficial cell layers (9). Therefore, the proximity of DCs to basal epithelial cells, which are considered to be the primary targets for HPV infection, could make DCs accessible for infection. Previous studies have shown that DCs express the $\alpha 6$ integrin receptor, which is associated with viral entry $(18,19)$. Additionally, human monocytes and macrophages are known to be susceptible to bovine papillomavirus infection in vitro (20).

Spontaneous regression of flat warts is believed to be associated with activation of a cellular immune response against HPV-infected keratinocytes (21). Initiation of this response depends upon HPV antigen presentation by DCs. The contribution of HPV-infected basal keratinocytes as non-professional antigen-presenting cells is most likely insignificant in light of their low-level expression of E6 and E7 as well as their lack of the receptors necessary to mount an effective immune response $(22,23)$. Therefore, it is possible that professional antigen presenting cells such as LCs and DCs transport HPV antigens from the skin or mucosal tissues to draining lymph nodes where the antigens are presented to specific naive $\mathrm{T}$ cells (11). This view is supported by studies in vitro, which show that DCs are capable of initiating an immune response after priming with viral proteins E6 and E7 (24). However, if this occurs, it most likely happens at late stages of infection in that seroconversion associated with high-risk forms of HPV typically takes nine months on average from the first detection of HPV DNA in a cervical biopsy (25).

Taken together, published studies indicate that DC activation is a crucial factor in anti-HPV protection. Lack of an in vitro system for productive infection of DCs with HPVs, prompted us to examined human DCs transfected with constructs containing the HPV genome. Our data suggest that HPV transfection of DCs leads to changes in DC migratory activity and cytokine production, which potentially may suppress or delay an immune response to viral antigens. Additionally, changes in cytokine production by HPV-transformed human foreskin fibroblasts (HFFs) and human cervical epithelial cells reveals that DC migratory and antigen-presenting functions may be impaired by the suppressive effects of cytokines produced by HPV-infected epithelial and stromal cells.

\section{Materials and methods}

Cell lines and media. The DC line RAN1 was previously generated from cells obtained from a patient with histiocytic lymphoma by using several rounds of selection and limiting dilution in order to obtain monoclonality (52). HFFs were from Cellular Engineering Technologies, Coralville, IA, USA; the HPV18-infected C4-II cell line was obtained from ATCC (ATCC ${ }^{\circledR}$ CRL1595 ${ }^{\mathrm{TM}}$ ); and normal human cervical cells epithelial cells (NHCEC) cells were originally purchased from Bio-Whittaker (now Lonza, Inc., Allendale, NJ, USA). All cell lines, except NHCEC cells, were grown in Dulbecco's modified Eagle's medium (DMEM) supplemented with gluta- mine and 20\% fetal bovine serum (FBS, Atlanta Biologicals, Norcross, GA, USA). KGM-2 medium containing epidermal growth factor, insulin, hydrocortisone and bovine pituitary extract (Lonza Inc.) was used to grow NHCEC cells.

Plasmid and transfection. The GFP Fusion TOPO cloning vector (Life Technologies, Carlsbad, CA, USA) was used to create a GFP-HPV18 plasmid containing the full length HPV18 genome. The HPV18 genome was purchased from ATCC (ATCC $45152^{\mathrm{TM}}$ ). Originally linearized at the unique EcoRI site and cloned into the pBR322 vector (53), the HPV18 genome DNA was digested with XmnI and NheI, purified and ligated into the NheI-EcoRV-cut GFP Fusion TOPO cloning vector.

DCs or HFFs were seeded into 24 -well plates $\left(2.0 \times 10^{4}\right.$ cells per well) and grown to $75-80 \%$ confluency. Transfection of cells was performed using Lipofectamine ${ }^{\mathrm{TM}}$ reagent (Life Technologies). GFP-HPV18 plasmid DNA $(2 \mu \mathrm{g})$ and Lipofectamine reagent $(10 \mu \mathrm{l})$ were mixed in serumreduced medium (Opti-MEM ${ }^{\circledR}$ medium, Life Technologies) and incubated for $45 \mathrm{~min}$ at $21^{\circ} \mathrm{C}$. Cell monolayers, washed once with Opti-MEM medium, were overlaid with $1 \mathrm{ml}$ of preformed lipid-DNA complexes. After $5 \mathrm{~h}$ of incubation at $37^{\circ} \mathrm{C}$ in $5 \% \mathrm{CO}_{2}, 1 \mathrm{ml}$ of culture medium containing $20 \%$ FBS was added. Culture medium was refreshed $24 \mathrm{~h}$ after initiation of transfection. Cells were harvested at $72 \mathrm{~h}$ posttransfection and grown in selection medium containing G418 sulfate (Geneticin ${ }^{\circledR}$, Life Technologies). The appropriate concentration of selection antibiotic was determined in prior experiments by titration of LD50 and varied depending on the cell line $(2.5 \mathrm{mg} / \mathrm{ml}$ for DCs and $250 \mu \mathrm{g} / \mathrm{ml}$ for HHFs). The appearance of transfected colonies was detected by light microscopy 5-7 days after initiating selection. HHFs and DCs were transfected with GFP Fusion TOPO cloning plasmid to generate stably transfected cell lines.

RT-PCR detection of E6 and E7 transcripts. Total RNA from C4-II cells and HPV18-transfected DCs and HFFs was extracted using TRIzol ${ }^{\circledR}$ reagent (Life Technologies). DNA contamination of RNA samples was prevented by treatment with DNase (Life Technologies) according to the manufacturer's recommendation. cDNA was amplified using Super Script kit (Life Technologies) according to the manufacturer's instructions. Ten microliters of cDNA was mixed with $4 \mu \mathrm{l}$ 10X PCR buffer, $2 \mu 125 \mathrm{mM} \mathrm{MgCl} \mathrm{M}_{2}, 0.5 \mu \mathrm{l}$ (100 pmol) of each primer, $32.7 \mu \mathrm{l}$ distilled water and $0.3 \mu \mathrm{l}(2.5 \mathrm{U})$ Taq DNA polymerase. The reaction mixture was then subjected to 35 cycles, each consisting of $30 \mathrm{sec}$ at $94^{\circ} \mathrm{C}, 30 \mathrm{sec}$ at $50^{\circ} \mathrm{C}$ and $2 \mathrm{~min}$ at $72^{\circ} \mathrm{C}$. The amplified products were sequenced to confirm HPV18 DNA. Primers used were: 5'-GTGAGAA ACACACCACAATACTATG-3' forward and 5'-CTCTGCGT CGTTGGAGTCGTTC-3' reverse, which amplify the E6 product of $328 \mathrm{bp}$ and 5'-CGGACACACAAAGGACAGGG-3' forward and 5'-GACGCAGAGAAACACAAGTATAATA-3' reverse which amplified the E7 products of 485- or 302-bp (spliced) fragments.

Immunoprecipitation and western blot analysis. Expression of HPV18 proteins was evaluated by immunoprecipitation and western blotting. HPV18-transfected and non-transfected cells 
were collected after trypsinization, pelleted $(1,000 \mathrm{rpm}, 5 \mathrm{~min})$ and lysed by suspension in $200 \mu 1$ of PBS with $1 \%$ Triton X-100 and protease inhibitors (1:10; Complete Mini, Roche, Indianapolis, IN, USA). Cell debris was removed by centrifugation at 3,000 rpm for $5 \mathrm{~min}$ and supernatants were stored at $-70^{\circ} \mathrm{C}$ prior to use. Protein G Plus-Agarose (P-A, $100 \mu \mathrm{l}$; Santa Cruz Biotechnology, Santa Cruz, CA, USA) was washed twice in PBS ( $\mathrm{pH}$ 7.2) and incubated with monoclonal anti-L1 HPV coat protein antibody (Novocastra, Burlingame, CA, USA) or anti-E6-protein monoclonal antibody (Calbiochem, La Jolla, CA, USA) for $2 \mathrm{~h}$ at room temperature. Protein $\mathrm{G}$ Plus-Agarose-antibody complexes (P-AA) were washed twice in PBS (pH 7.2) and incubated $12 \mathrm{~h}$ with clarified cell supernatant at $4^{\circ} \mathrm{C}$. P-AA complexes with bound antigen were centrifuged briefly at $1,000 \mathrm{rpm}$ for $5 \mathrm{~min}$, washed in PBS (pH 7.2) twice and incubated with $1 \%$ SDS loading buffer for $5 \mathrm{~min}$ at room temperature. Agarose beads were removed by centrifugation and samples were analyzed by SDS-PAGE electrophoresis. Proteins were standardized using a modified Lowry protein assay (Pierce, Rockford, IL, USA) and was verified by Coomassie staining of the gel. Additionally, quantitative loading of proteins was determined by probing the nitrocellulose membrane with anti-actin antibodies (Santa Cruz Biotechnology). Proteins were electroblotted (15 min, $4 \mathrm{~mA} / \mathrm{cm}^{2}$ ) onto nitrocellulose membranes (Bio-Rad, Hercules, CA, USA) and blocked for $1 \mathrm{~h}$ at room temperature with 5\% milk in Tris-buffered saline (TBS) and 0.5\% Tween-20. After three washes, membranes were incubated with monoclonal anti-HPV L1 antibodies (1:50; Novocastra) or anti-E6-protein monoclonal antibodies (1:25; Calbiochem) for $12 \mathrm{~h}$ at room temperature. Antigen-antibody complexes were identified with HRP-conjugated goat anti-mouse antibodies and developed using DAB (3, 3'-diaminobenzidine) substrate (Vector Laboratories, Inc., Burlingame, CA, USA).

Cytokine ELISA. Tumor necrosis factor- $\alpha$ (TNF- $\alpha)$ interleukin-6 (IL-6), transforming growth factor- $\beta$ (TGF- $\beta$ ) and monocyte chemotactic protein-1 (MCP-1) ELISA kits were purchased from Life Technologies. The selection of cytokines for this study was based upon published data suggesting their involvement in mechanisms controlling tumor growth or regression (14,30,36-38). Transfected and non-transfected cells $\left(10^{6}\right.$ cells/well $)$ were placed in 12 -well plates and grown to confluency and activated with lipopolysaccharide ( $1 \mu \mathrm{g} / \mathrm{ml}$; LPS; Sigma Chemical Co., St. Louis, MO, USA). Forty-eight hours after addition of LPS, growth medium was collected and stored at $-80^{\circ} \mathrm{C}$ until analyzed.

Southern blot analysis. An HPV18 ${ }^{32} \mathrm{P}$-end-labeled DNA probe was generated using a DNA labeling kit (Ready-To-Go, GE Healthcare Life Sciences Inc., Piscataway, NJ, USA), $50 \mu \mathrm{Ci}\left[\alpha^{32} \mathrm{P}\right]$-dCTP and $\sim 50 \mathrm{ng}$ of HPV18 plasmid DNA. After a 15 -min incubation at $37^{\circ} \mathrm{C}$, MicroSpin G-50 columns (GE Healthcare Life Sciences Inc.) were used to purify the labeled DNA. A DNA isolation kit (Puregene ${ }^{\circledast}$ DNA, Qiagen, Valencia, CA, USA) was used for extraction of DNA from HPV-transfected cell lines. Approximately $10 \mu \mathrm{g}$ of DNA was digested with EcoR1 restriction enzyme (New England Biolab; Beverly, MA, USA) and resolved on a $1.0 \%$ agarose gel. Denatured DNA $(0.25 \mathrm{~N} \mathrm{HCl}$ for $10 \mathrm{~min})$ was trans- ferred by capillary to nylon membranes (ZetaProbe Nylon, Bio-Rad). The membranes were incubated $14 \mathrm{~h}$ at $55^{\circ} \mathrm{C}$ with labeled HPV18 DNA (5 ng) in $10 \mathrm{ml}$ of hybridization buffer [1.5X SSPE, 7\% SDS, $10 \%$ (wt/vol) polyethylene glycol 4000]. The blots were washed twice for 15 min each at room temperature with 2 X SSC-1\% SDS and then twice with 0.1X SSC-1\% $\mathrm{SDS}$ for $25 \mathrm{~min}$ each at $55^{\circ} \mathrm{C}$. The blots were then exposed to $\mathrm{X}$-ray film for $15 \mathrm{~h}$ at $-80^{\circ} \mathrm{C}$.

Northern blot analysis. In order to recover total intracellular RNA, cells were washed with PBS (pH 7.2) and lysed with TRIzol reagent according to the manufacturer's instructions. RNA (20-50 $\mu \mathrm{g})$ was denatured for $15 \mathrm{~min}$ at $70^{\circ} \mathrm{C}$ in RNA buffer [50\% formamide, $5 \%$ formaldehyde, 1X morpholinepropanesulfonic acid (MOPS)], separated on a 3\% formaldehyde-agarose gel and transferred to a nylon membrane (ZetaProbe Nylon). Membranes were hybridized with ${ }^{32} \mathrm{P}$-labeled plasmid for $14 \mathrm{~h}$ at $60^{\circ} \mathrm{C}$ and washed as described above. A ${ }^{32} \mathrm{P}$-labeled $18 \mathrm{~S}$ ribosomal RNA probe (Ambion, Austin, TX, USA) was used to standardize loading.

Colony formation assay. HPV18 transfected and nontransfected cells $\left(10^{6} /\right.$ well in 12 -well plates) were placed in methylcellulose medium ( $3 \mathrm{ml}$; Life Technologies) containing $20 \%$ FBS (Atlanta Biologicals) and L-glutamine (Life Technologies). After 14 days of culture, colonies were counted under light microscopy.

Chemotaxis assay. The in vitro migration of DCs was assayed in 24-well transwell cell culture chambers (54). DCs were washed and suspended in DMEM, supplemented with $20 \%$ FBS. Filter inserts $(8 \mu \mathrm{m})$ were placed into the cell culture plate wells to create upper and lower compartments. DCs $\left(5 \times 10^{4}\right)$ were applied into the upper chamber, while the lower chamber was filled with $200 \mu$ l of medium (DMEM + $20 \%$ FBS) containing $50 \mu \mathrm{g}$ of GM-CSF. After $4 \mathrm{~h}$ of incubation $\left(37^{\circ} \mathrm{C}, 5 \% \mathrm{CO}_{2}\right)$, cells in the upper side of the filter were removed and filters were scraped to remove residual cells. Filters were fixed (3:1 methanol/acetone mixture, $5 \mathrm{~min}$ ) and cellular nuclei were stained with hematoxylin. Five random microscopic fields were counted per filter to evaluate the number of migrated cells.

Statistical analysis. Statistical significance was assessed by the Student's paired $t$-test and considered significant at $\mathrm{P}<0.05$.

\section{Results}

Characterization of HPV18-transfected DCs. Because of difficulties in propagating papillomaviruses and generating infectious virus in vitro, we used DNA transfection to deliver viral DNA into DCs. One week after transfection, colonies of DCs were isolated and subcultured for an additional 2-3 passages. A stably transfected DC line, which persistently maintained the HPV18 genome, was utilized for experiments reported herein.

It has been reported that HPV DNA regularly becomes integrated into host cell DNA (1). Therefore, it was of interest to determine if our HPV18 DNA construct is maintained as a plasmid or integrated into the genome. Total DNA from trans- 


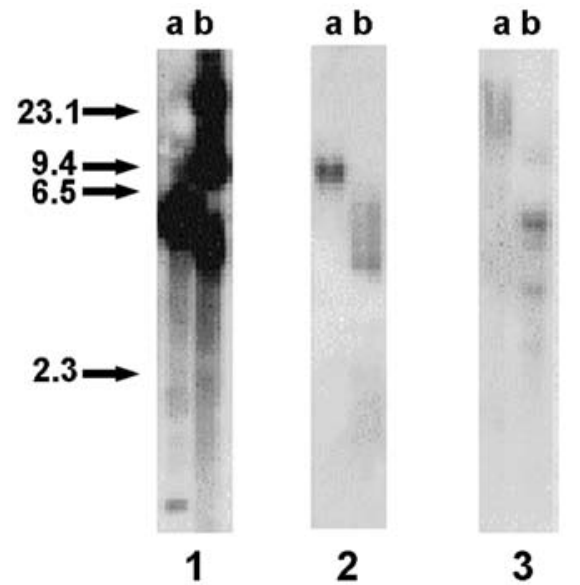

Figure 1. Southern blot analysis of transfected cell cultures demonstrating integration of HPV18 genomes. Total genomic DNA $(10 \mu \mathrm{g})$ was not digested (column a) or digested with EcoR1 restriction enzyme (column b) linearizing the $8.0 \mathrm{~kb}$ HPV18 genome. Lane 1, total DNA from HPV18 transfected DC; lane 2, total DNA from HPV18 transfected HFF; lane 3, total DNA from HPV18 transformed cervical keratinocytes.

fected DCs was isolated as described in Materials and methods. Southern blot analysis revealed integration of HPV18 DNA into the DC genome; no extra-chromosomal plasmid could be detected in DNA samples isolated from transfected cells following cleavage with EcoRI (Fig. 1, lane 1). Transfection did not induce differentiation of DCs to a more mature or macrophage-like phenotype or change their growth pattern (data not shown).

L1 is the major HPV capsid protein and is highly conserved among all papillomaviruses. Since expression of papillomavirus L1 protein is important for development of an anti-HPV immune response (26-29), we sought to establish if HPV18transfected cells express this protein. Immunoprecipitation and western blot analysis established that $\mathrm{L} 1$ protein was present only in extracts of transfected cells (Fig. 2). To confirm these data, we further analyzed extracts for the presence of L1 mRNA. Total RNA from transfected and non-transfected cells was collected and subjected to northern blot analysis. Consistent with our western blot results, HPV L1 specific transcripts were detected only in HPV18 transfected DCs, whereas no HPV RNA was found in non-transfected DC control (Fig. 3).

It is well documented that HPV18 E6 and E7 proteins are important in cell transformation; therefore, transcription of E6 and E7 genes was analyzed by RT-PCR. Amplicons consistent with the expected RT-PCR product of the E6 and E7 gene ( $\sim 302$ and 485 bp for E6 and $\sim 328$ bp for E7) were detected in transfected DC cells (Fig. 4A, lane 1 and B, lane 1). Sequencing of the excised bands confirmed these results.

In view of the possibility that expression of viral transcripts or proteins could influence immune functions, IL-6, MCP-1, TGF- $\beta$ and TNF- $\alpha$ expression was analyzed in transfected and non-transfected DCs. Selection of cytokines was based upon previous reports on their importance in HPV-associated cervical neoplasia $(30,31)$ or their in vitro expression following DC exposure to HPV proteins $(24,32)$. To determine the effect of HPV18 transfection on cytokine production, transfected DCs, non-transfected DCs and DCs transfected with empty

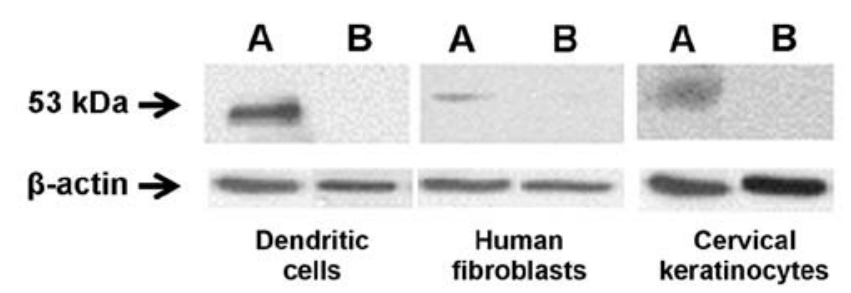

Figure 2. Western blot analysis of L1 protein expression in HPV transfected and non-transfected cells. (A) Transfected cells. (B) Non-transfected control.

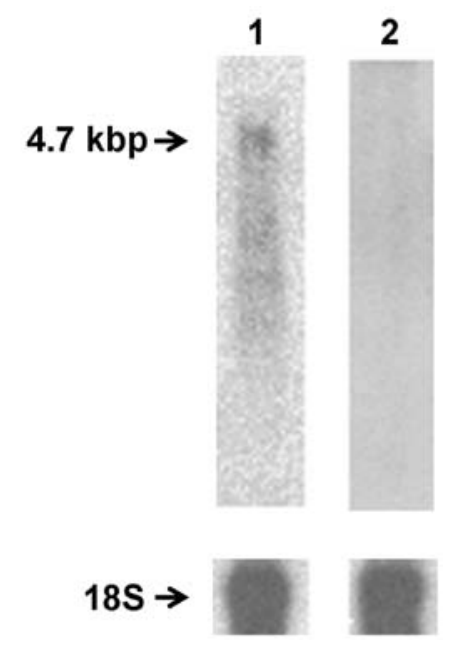

Figure 3. Northern blot analysis of L1 transcripts in HPV18 transfected DCs. Membranes were hybridized with ${ }^{32} \mathrm{P}$-labeled HPV18 plasmid from HPV transfected DC (lane 1) and non-transfected DCs (lane 2). A ${ }^{32}$ P-labeled $18 \mathrm{~S}$ ribosomal RNA probe was used to standardize loading.

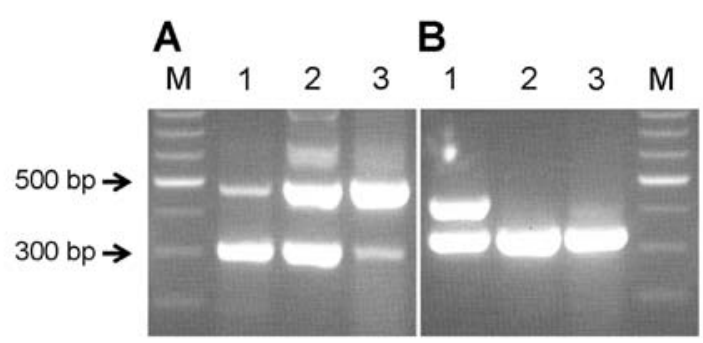

Figure 4. Detection of HPV18 E6/7 transcripts in HPV18 transformed cells. Total RNA from HPV18-transformed C4-II cells and HPV18-transfected DCs and HFFs was collected and used to detect E6 and E7 transcript by RT-PCR. E6 transcript amplification (A). E7 transcript amplification. (B) Lane 1, RNA from HPV18 transfected DC. Lane 2, RNA from HPV18 transfected HF cells. Lane 3, RNA from C4-II cells. Lane M, marker.

vector were cultured to confluency. As a positive control for cytokine production, LPS $(1 \mu \mathrm{g} / \mathrm{ml})$ was added to the medium of both transfected and non-transfected cell lines. Transfection with the empty vector did not influence cytokine production (data not shown). IL-6, TGF- $\beta$ and TNF- $\alpha$ production was significantly increased in supernatants of HPV18-transfected DCs compared to non-transfected controls (Fig. 5A-C). LPS stimulation resulted in upregulation of IL- 6 and TNF- $\alpha$ by both non-transfected and transfected cells; however, the increases in IL-6 and TNF- $\alpha$ production following LPS 
A
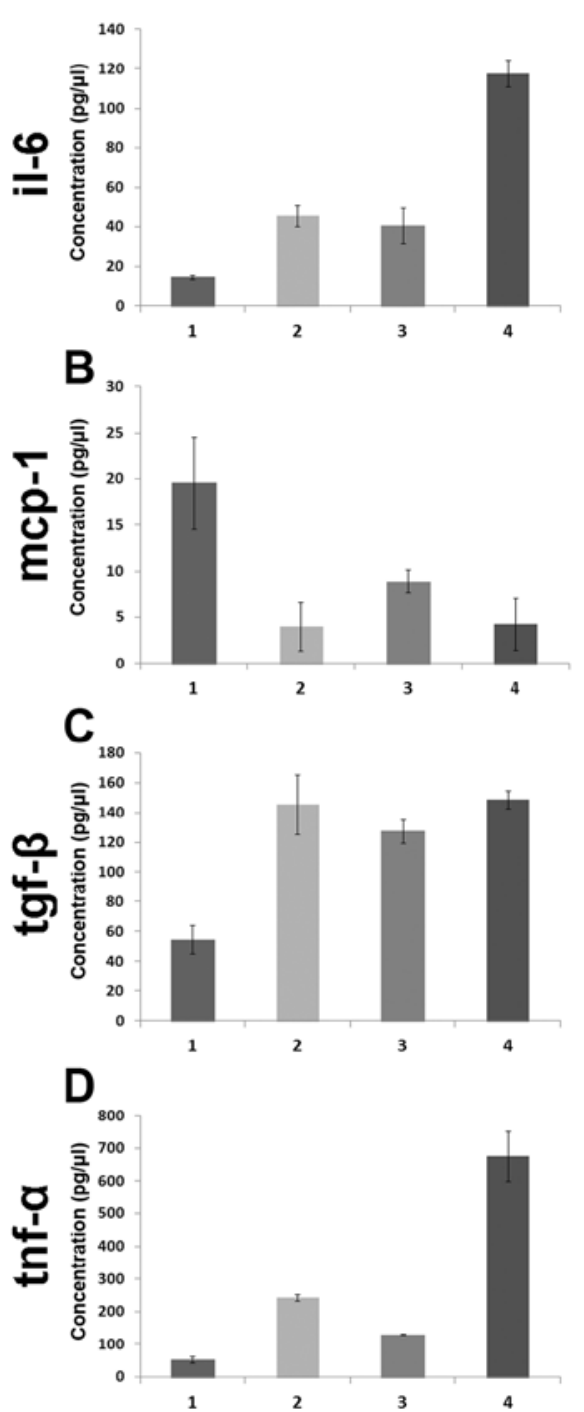

E Human fibroblasts
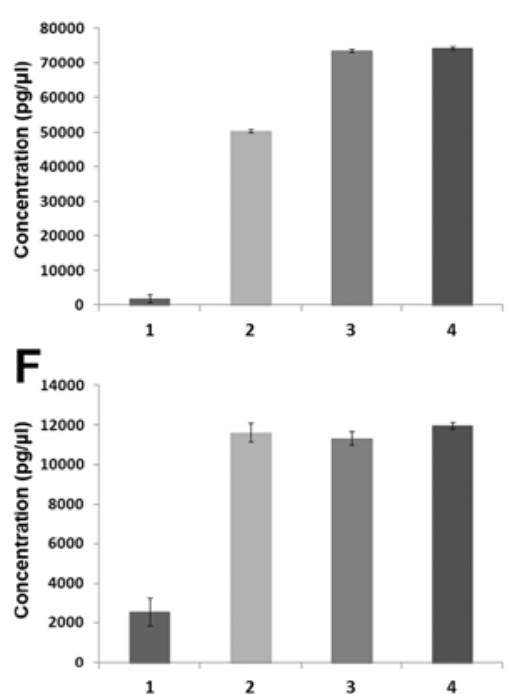

G

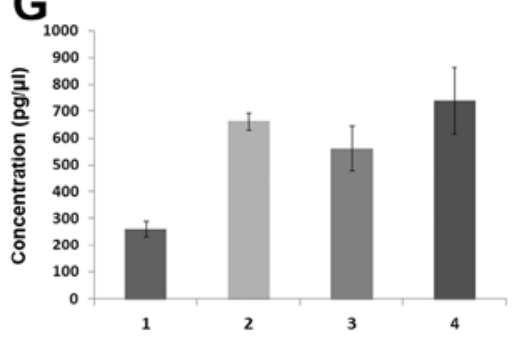

H

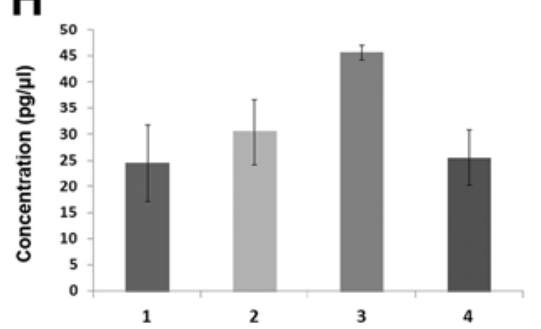

\section{Cervical keratinocytes}
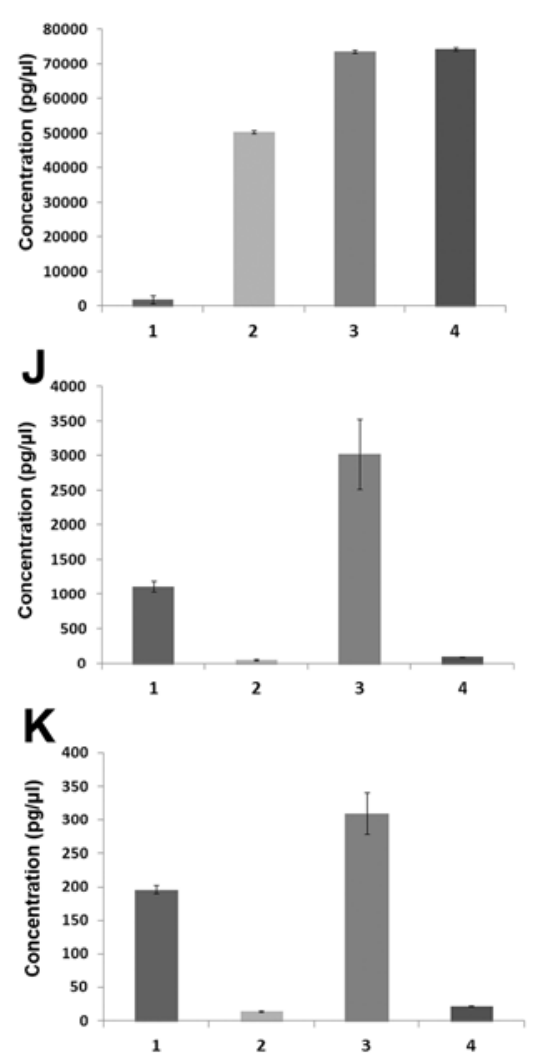

1 - Non-transformed cells

2 - Transformed cells

3 - Non-transformed cells + LPS

4 - Transformed cells + LPS

Figure 5. Analysis of cytokine production by HPV18 transfected and non-transfected cells. Transfected and non-transfected cells were placed in 12 -well plates, grown to confluency and activated as indicated by the addition of lipopolysaccharide. Growth medium was collected and used to determine cytokine/ chemokine concentration by ELISA.

stimulation were greater in HPV-transfected cells than in nontransfected controls. LPS treatment of non-transfected DCs increased TGF- $\beta$ production, as did transfection with the HPV construct. However, LPS stimulation of HPV18 transfected DCs did not cause further upregulation of TGF- $\beta$ compared to non-transfected cells. The concentration of MCP-1 was significantly decreased in supernatants of HPV-transfected DCs versus non-transfected cells (Fig. 5B).

Migration of DCs from the site of infection to the regional lymph nodes is essential for induction of an effective immune response; therefore, changes in the migratory function due to HPV infection, may potentially impact the outcome of an antiHPV immune response. To determine if HPV18 transfection might influence the migration of DCs, we conducted migration assays using a Boyden microchemotaxis chamber. Chemotaxis was significantly enhanced by addition of GM-CSF to the medium (Fig. 6). Spontaneous motility of DCs transfected with HPV18 was significantly higher than that of non-trans- fected cells. However, the chemotactic response of transfected DCs was significantly lower than that of non-transfected cells, although it remained higher than the response to nonconditioned medium. The presence of the empty vector control did not affect DC migration (data not shown).

Characterization of human foreskin fibroblasts (HFF) transfected with HPV18 DNA and HPV18-infected human cervical epithelial cells (C4-II). HPV18 infects basal epithelial cells of the cervix, therefore, cytokines produced by cervical epithelial cells and fibroblasts may influence the function of local DCs. For this reason, we sought to determine if HPV18 transformation promoted cytokine production in human fibroblasts and cervical epithelial cells. The HPV18-infected human cervical epithelial cell line (C4-II) has been shown to maintain an expression profile that accurately represents cervical cancer when compared to normal cervix biopsies (33). Therefore, this cell line was used to evaluate the effects of virus transforma- 


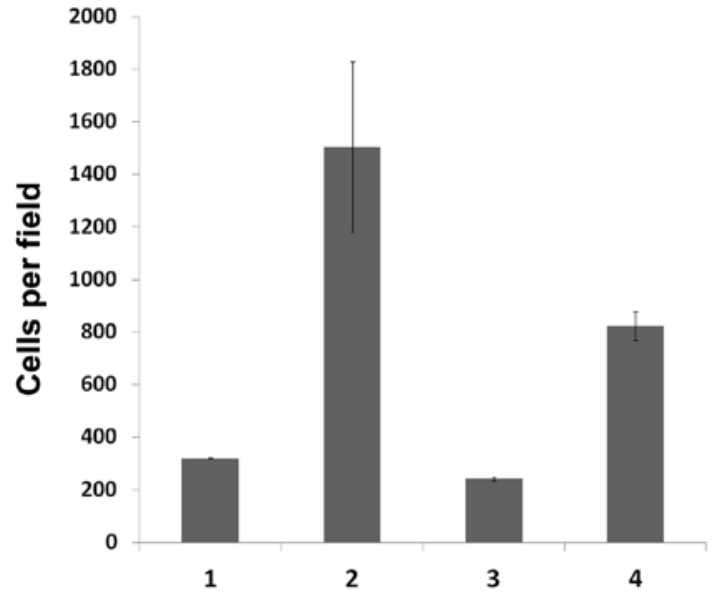

Figure 6. Analysis of migratory activity of HPV18 transfected DCs. DCs $\left(5 \times 10^{4}\right)$ were placed into the upper compartment of the Boyden chamber, while the lower chamber was filled with culture medium containing GM-CSF After $4 \mathrm{~h}$ of incubation, cells in the upper side of the filter were removed and filters were scraped to remove residual cells. Filters were fixed and cellular nuclei were stained with hematoxylin. Five random microscopic fields were counted per filter to evaluate the number of migrated cells. Bar 1, spontaneous migration of non-transfected DCs; bar 2, migration of non-transfected DC in the presence of GM-CSF $(50 \mathrm{ng} / \mu 1)$; bar 3, spontaneous migration of HPV18 transfected DCs; bar 4, migration of HPV18 transfected cells in the presence of GM-CSF $(50 \mathrm{ng} / \mu \mathrm{l})$.

tion on cytokine expression and growth patterns of cervical epithelial cells. Normal human cervical epithelial cells (NHCEC) were used as a control.

Human fibroblasts were transfected with HPV-GFP plasmid and cultured for selection of stably transfected cell colonies. A transformed cell line (HPV18-HFF) that persistently maintained the HPV18 genome was isolated and used in all further experiments. Southern blot analysis revealed genomic integration of viral DNA in transfected HFFs that was consistent with that observed in HPV18-infected C4-II cells (Fig. 1, lane 2). Additionally, transfected HFFs and HPV18-infected C4-II cells both expressed HPV18 L1 protein (Fig. 2), as detected by immunoprecipitation and western blotting.

In order to determine if transcriptional activation of the E6 and E7 genes could be detected in transfected HFFs and transformed C4-II cells, we again performed RT-PCR as described above. Consistent with our observations for DCs, transcriptional activation of the E6 and E7 genes was identified in HFFs and C4-II cells (Fig. 4). Significantly, HPV18 transfection resulted in transformation of HFFs as suggested by the colony formation assay (Fig. 7). Transfected HFFs were able to support anchorage-independent growth in soft agarose medium. In contrast, non-transfected HFFs failed to produce colonies in soft agarose. It has been reported that expression of E6 and E7 genes affect cell growth properties such as saturation density and colony formation in soft agarose $(34,35)$, consistent with our observations.

In view of our observation that HFFs and cervical epithelial cells were able to support the expression of some HPV18 proteins, we sought to determine if transfection with the HPV18 construct would influence cytokine production. Culture media from HPV18-transformed (HPV18-HFFs and C4-II) and non-transformed cells (HFFs and NHCEC) was analyzed for hpv-18
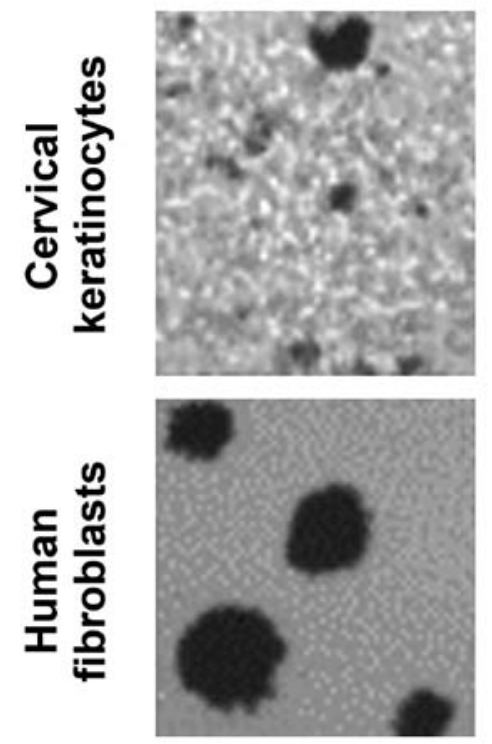

Control

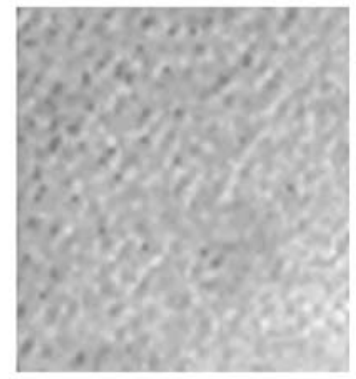

Figure 7. Analysis of anchorage independent growth of HPV18 transformed HF and cervical keratinocytes. HPV18 transfected and non-transfected were placed in methylcellulose medium containing $20 \%$ FBS and L-glutamine. After 14 days of culture, colonies were counted under light microscopy.

cytokine production by ELISA. HFFs transfected with empty vector were used as a negative control in all experiments and LPS treatment was used as a positive control. When compared to non-transfected cells, those transfected with empty vector consistently showed no difference in cytokine production (data not shown).

When compared to non-transformed cells, all transformed cells showed statistically significant differences in cytokine production (Fig. 5), with the greatest difference being a 60 -fold increase in IL-6 production (Fig. 5E and I). Interestingly, transformed keratinocytes were refractory in MCP- 1 and TGF- $\beta$ production, even upon LPS stimulation, when compared to their non-transformed counterparts (Fig. 5J and K). Additionally, upon LPS stimulation, transformed fibroblasts displayed decreased TNF- $\alpha$ production when compared to non-transformed cells (Fig. 5H).

\section{Discussion}

In order to investigate the possible consequence of HPV infection on DC functions we used transfection as a form of viral genome delivery. Transfection of DCs and expression of viral proteins did not result in cell death; conversely, we were able to develop several lines of DCs containing the complete HPV18 genome. Expression of L1 major capsid protein was revealed in western blot analyses, as were L1 transcripts by Southern blotting. Although evidence of E6 or E7 protein production was lacking in transfected DCs, all transfected cell lines expressed HPV18 E6 and E7 transcripts, suggesting possible low-level protein expression below the sensitivity of our detection method. Expression of the L1 protein by DCs may be important for stimulation of an antibody response 
against HPV. Indeed, Steele and Gallimore (28) observed the production of specific antibodies during the course of HPV infection, the majority of which were antiviral capsid proteins. They further reported that as papillomas progressed to carcinomas, there was a marked increase in the response to L1 and L2 suggesting a change in interaction between virus-infected host cells and the host's immune system $(26,27)$. However, it is believed that antibodies to capsid proteins are not sufficient to totally suppress infection (30) because of the limitation of HPV capsid protein expression to superficial epithelial cells, which do not represent the site of virus replication (3).

In our experiments, HPV18 transfection of DCs resulted in increased production of cytokines involved in DC migration. This phenomenon was accompanied by increased spontaneous migration of DCs after HPV18 transfection compared to nontransfected cells, suggesting that HPV18 transfection could activate cellular mechanisms controlling DC migration. It has been shown that TNF- $\alpha$ and IL- 6 contribute to the migration of DCs through the dermis in vivo and in vitro (36-38). Constitutive and inducible expression of IL-6 by DCs could facilitate the induction of cutaneous immune responses (36). Importantly, DCs are reported to be a significant source of IL-6 in lymph nodes during the primary immune responses to cutaneous antigens (39). Our data show that HPV18 transfection increases production of TNF- $\alpha$ and IL- 6 by DCs. This result suggests that HPV18-transfected DCs are potentially capable of inducing an immune response to viral proteins as a result of increased migratory activity and upregulation of cytokines involved in antigen priming of $\mathrm{T}$ cells in lymph nodes. Additionally, HPV-transfected DCs released significantly more inflammatory cytokines (TNF- $\alpha$ and IL-6) after LPS stimulation than non-transfected cells. These data suggest that papillomavirus may act as a cofactor for induction of proinflammatory cytokines in DCs when they are exposed to secondary inflammatory stimuli.

Keratinocytes are the primary target for papillomavirus infection (23). Previous studies have shown that keratinocytes secrete a variety of lymphokines that are critical components of the host response to infection or injury $(40,41)$. HPV infection may result in changes in cytokine production creating a favorable environment for viruses to evade clearance by immune cells $(3,14)$. In this study, we found that cervical epithelial keratinocytes and HFFs support expression of viral proteins. Although, HPV18 transfection altered cytokine production in keratinocytes and HFFs, these changes were cell-type specific.

Since several reports proposed MCP-1 and TGF- $\beta$ involvement in the pathogenesis of HPV-associated cervical neoplasms $(30,31)$, we studied production of these cytokines by HPV transfected cells. HPV18 infection of cervical keratinocytes significantly decreased production of MCP-1. Previous studies showed that MCP-1 plays an important role in recruitment of monocytes to areas of virus entry and activates these cells to secrete a variety of cytokines and chemokines $(42,43)$. It is believed that monocytes attracted into infected tissue can differentiate into a variety of cells, including DCs (44). Thus, a local decrease in MCP-1 might alter the mechanism of DC recruitment into tumor tissue leading to a decreased number of local DCs. Kleine and coworkers (45) reported rapid growth of tumors in nude mice inoculated with MCP-1-negative HeLa cells and suggested that this effect was a result of a decrease in macrophages migrating into the tumor tissue due to low levels of MCP-1 produced by the tumor cells.

Decreases in TGF- $\beta$ production by transformed keratinocytes may also contribute to long-term maintenance of papillomavirus infection. TGF- $\beta$ is an important factor in differentiating HPV-infected keratinocytes. For example, TGF- $\beta$ treatment of cultured monolayers is accompanied by downregulation of HPV E6 and E7 transcription (46). Treatment of organotypic cultures with TGF- $\beta$ results in renewed ability of keratinocytes to express morphological and biochemical markers, characteristic of a more normal and differentiated phenotype (47). Previous studies established that TGF- $\beta$ stimulation is requisite for the development of DCs in vitro and in vivo $(48,49)$ and is involved in the reciprocal control of DC chemotaxis (50). In addition, TGF- $\beta$ inhibits upregulation of critical T-cell costimulatory molecules on the surface of DCs. Furthermore, TGF- $\beta$ appears to enhance antigen processing and costimulatory functions of epithelial LCs (reviewed by Strobl and Knapp) (51). Thus, a decrease in local TGF- $\beta$ as a result of HPV infection may abrogate mechanisms of immune recognition and/or stimulation and suppress DC migratory ability.

The reaction of human HFFs to HPV18 transformation differed markedly from that of cervical keratinocytes. For example, HPV18-HFFs produced significantly more MCP-1 and TGF- $\beta$ than non-transformed cells, whereas cervical keratinocytes responded in the opposite manner. The increases in cytokine production by HPV18-HFFs suggest that HPV transformation may lead to the development of a localized tissue environment supportive for increased DC numbers and differentiation. HFFs are a main component of the subepithelial stroma. Previous studies have shown that the immunological reactions of tumor tissue and peritumoral stroma may be different. For example, Beutner and Tyring (22) found that, if immature DCs are predominantly localized in breast carcinoma tissue, mature DCs adhere selectively to peritumoral areas. Mota and coworkers (14) discovered that $\mathrm{CD}^{+} \mathrm{DCs}$ were occasionally detected in cervical intraepithelial neoplastic lesions; however, leucocytes with an activated phenotype accumulated immediately below the epithelial lesions in subepithelial stroma (24). These observations and data presented here, are consistent with the proposal that HFFs expressing papillomavirus proteins develop an immunoactivating cytokine profile; nevertheless, additional investigations are necessary to delineate the role of stromal HFFs in pathogenesis of papillomavirus infection.

\section{Acknowledgements}

Work conducted in the laboratory of V.C.L. was supported, in part, by an award from the U.S. Department of Health and Human Services, HERSA award C76HF19321; work conducted in the laboratory of A.A.R. by FCP No. 14.A18.21.1930, Russian Federation President Grant for young scientists (Dr.Sci.) МД-433.2013.4, as well as the Federal Center of Collective Use and Pharmaceutical Research and Education Center, Kazan (Volga Region) Federal University, Kazan, Russia. 


\section{References}

1. zur Hausen H: Papillomavirus infections - a major cause of human cancers. Biochim Biophys Acta 1288: F55-F78, 1996.

2. Kanodia S, Fahey LM and Kast WM: Mechanisms used by human papillomaviruses to escape the host immune response. Curr Cancer Drug Targets 7: 79-89, 2007.

3. Frazer IH: The role of the immune system in anogenital human papillomavirus. Australas J Dermatol 39 (Suppl 1): S5-S7, 1998

4. al-Saleh W, Giannini SL, Jacobs N, et al: Correlation of T-helper secretory differentiation and types of antigen-presenting cells in squamous intraepithelial lesions of the uterine cervix. J Pathol 184: 283-290, 1998.

5. Coleman N, Birley HD, Renton AM, et al: Immunological events in regressing genital warts. Am J Clin Pathol 102 768-774, 1994.

6. al-Saleh W, Delvenne P, Arrese JE, Nikkels AF, Pierard GE and Boniver J: Inverse modulation of intraepithelial Langerhans cells and stromal macrophage/dendrocyte populations in human papillomavirus-associated squamous intraepithelial lesions of the cervix. Virchows Arch 427: 41-48, 1995.

7. McArdle JP and Muller HK: Quantitative assessment of Langerhans' cells in human cervical intraepithelial neoplasia and wart virus infection. Am J Obstet Gynecol 154: 509-515, 1986.

8. Morelli AE, Sananes C, Di Paola G, Paredes A and Fainboim L: Relationship between types of human papillomavirus and Langerhans' cells in cervical condyloma and intraepithelial neoplasia. Am J Clin Pathol 99: 200-206, 1993.

9. Morris HH, Gatter KC, Stein H and Mason DY: Langerhans' cells in human cervical epithelium: an immunohistological study. Br J Obstet Gynaecol 90: 400-411, 1983.

10. Viac J, Guerin-Reverchon I, Chardonnet $\mathrm{Y}$ and Bremond A: Langerhans cells and epithelial cell modifications in cervical intraepithelial neoplasia: correlation with human papillomavirus infection. Immunobiology 180: 328-338, 1990.

11. Abbas AK, Lichtman AH and Pober JS: Cellular and Molecular Immunology. Saunders, Philadelphia, PA, 1997.

12. Breathnach SM: The Langerhans cell. Br J Dermatol 119: 463-469, 1988.

13. Melief CJ: Dendritic cells as specialized antigen-presenting cells. Res Immunol 140: 902-906; discussion 918-926, 1989.

14. Mota F, Rayment N, Chong S, Singer A and Chain B: The antigen-presenting environment in normal and human papillomavirus (HPV)-related premalignant cervical epithelium. Clin Exp Immunol 116: 33-40, 1999.

15. Hubert P, van den Brule F, Giannini SL, Franzen-Detrooz E, Boniver $J$ and Delvenne P: Colonization of in vitro-formed cervical human papillomavirus-associated (pre)neoplastic lesions with dendritic cells: role of granulocyte/macrophage colony-stimulating factor. Am J Pathol 154: 775-784, 1999.

16. Arany I, Goel A and Tyring SK: Interferon response depends on viral transcription in human papillomavirus-containing lesions. Anticancer Res 15: 2865-2869, 1995.

17. Park JS, Kim EJ, Kwon HJ, Hwang ES, Namkoong SE and Um SJ: Inactivation of interferon regulatory factor-1 tumor suppressor protein by HPV E7 oncoprotein. Implication for the E7-mediated immune evasion mechanism in cervical carcinogenesis. J Biol Chem 275: 6764-6769, 2000.

18. Evander M, Frazer IH, Payne E, Qi YM, Hengst K and McMillan NA: Identification of the alpha6 integrin as a candidate receptor for papillomaviruses. J Virol 71: 2449-2456, 1997.

19. Price AA, Cumberbatch M, Kimber I and Ager A: Alpha 6 integrins are required for Langerhans cell migration from the epidermis. J Exp Med 186: 1725-1735, 1997.

20. Bonnez W, Reichman RC, Strussenberg J and Roberts NJ Jr: In vitro interactions between bovine papillomavirus and human monocytes and macrophages. Intervirology 32: 246-252, 1991.

21. Tagami H, Oguchi M and Ofuji S: The phenomenon of spontaneous regression of numerous flat warts: immunohistological studies. Cancer 45: 2557-2563, 1980.

22. Beutner KR and Tyring S: Human papillomavirus and human disease. Am J Med 102: 9-15, 1997.

23. Shah KV and Howley PM: Papillomaviruses. In: B.N. Fields, D.M. Knipe and M. Howley (eds.), Fields Virology, 3rd edition Lippincott-Raven Publishers, Philadelphia, PA, pp2077-2109, 1996.

24. Le Buanec H, D'Anna R, Lachgar A, et al: HPV-16 E7 but not E6 oncogenic protein triggers both cellular immunosuppression and angiogenic processes. Biomed Pharmacother 53: 424-431, 1999.
25. Carter JJ, Koutsky LA, Hughes JP, et al: Comparison of human papillomavirus types 16,18 , and 6 capsid antibody responses following incident infection. J Infect Dis 181: 1911-1919, 2000

26. Lin YL, Borenstein LA, Selvakumar R, Ahmed R and Wettstein FO: Progression from papilloma to carcinoma is accompanied by changes in antibody response to papillomavirus proteins. J Virol 67: 382-389, 1993

27. Park JS, Park DC, Kim CJ, et al: HPV-16-related proteins as the serologic markers in cervical neoplasia. Gynecol Oncol 69: 47-55, 1998.

28. Steele JC and Gallimore PH: Humoral assays of human sera to disrupted and nondisrupted epitopes of human papillomavirus type 1. Virology 174: 388-398, 1990

29. Suzich JA, Ghim SJ, Palmer-Hill FJ, et al: Systemic immunization with papillomavirus L1 protein completely prevents the development of viral mucosal papillomas. Proc Natl Acad Sci USA 92: 11553-11557, 1995.

30. Frazer IH, Thomas R, Zhou J, et al: Potential strategies utilised by papillomavirus to evade host immunity. Immunol Rev 168: 131-142, 1999.

31. Rosl F, Lengert M, Albrecht J, et al: Differential regulation of the JE gene encoding the monocyte chemoattractant protein (MCP-1) in cervical carcinoma cells and derived hybrids. J Virol 68: 2142-2150, 1994.

32. Santin AD, Hermonat PL, Ravaggi A, et al: Development, characterization and distribution of adoptively transferred peripheral blood lymphocytes primed by human papillomavirus 18 E7 - pulsed autologous dendritic cells in a patient with metastatic adenocarcinoma of the uterine cervix. Eur J Gynaecol Oncol 21: 17-23, 2000.

33. Carlson MW, Iyer VR and Marcotte EM: Quantitative gene expression assessment identifies appropriate cell line models for individual cervical cancer pathways. BMC Genomics 8: 117, 2007.

34. Miyasaka M, Takami $Y$, Inoue $H$ and Hakura A: Rat primary embryo fibroblast cells suppress transformation by the E6 and E7 genes of human papillomavirus type 16 in somatic hybrid cells. J Virol 65: 479-482, 1991

35. Yutsudo M, Okamoto Y and Hakura A: Functional dissociation of transforming genes of human papillomavirus type 16. Virology 166: 594-597, 1988.

36. Cumberbatch M, Dearman RJ and Kimber I: Constitutive and inducible expression of interleukin- 6 by Langerhans cells and lymph node dendritic cells. Immunology 87: 513-518, 1996.

37. Saitoh A, Yasaka N, Osada A, Nakamura K, Furue M and Tamaki K: Migration of Langerhans cells in an in vitro organ culture system: IL-6 and TNF-alpha are partially responsible for migration into the epidermis. J Dermatol Sci 19: 166-174, 1999.

38. Stoitzner P, Zanella M, Ortner U, et al: Migration of langerhans cells and dermal dendritic cells in skin organ cultures: augmentation by TNF-alpha and IL-1beta. J Leukoc Biol 66: 462-470, 1999.

39. Hope JC, Cumberbatch M, Fielding I, Dearman RJ, Kimber I and Hopkins SJ: Identification of dendritic cells as a major source of interleukin-6 in draining lymph nodes following skin sensitization of mice. Immunology 86: 441-447, 1995.

40. Gibran NS, Ferguson M, Heimbach DM and Isik FF: Monocyte chemoattractant protein-1 mRNA expression in the human burn wound. J Surg Res 70: 1-6, 1997.

41. Shreedhar V, Giese T, Sung VW and Ullrich SE: A cytokine cascade including prostaglandin E2, IL-4, and IL-10 is responsible for UV-induced systemic immune suppression. J Immunol 160: 3783-3789, 1998.

42. Mantovani A, Bottazzi B, Colotta F, Sozzani S and Ruco L: The origin and function of tumor-associated macrophages. Immunol Today 13: 265-270, 1992.

43. Miller MD and Krangel MS: Biology and biochemistry of the chemokines: a family of chemotactic and inflammatory cytokines. Crit Rev Immunol 12: 17-46, 1992.

44. Muller WA and Randolph GJ: Migration of leukocytes across endothelium and beyond: molecules involved in the transmigration and fate of monocytes. J Leukoc Biol 66: 698-704, 1999.

45. Kleine K, Konig G, Kreuzer J, Komitowski D, Zur Hausen H and Rosl F: The effect of the JE (MCP-1) gene, which encodes monocyte chemoattractant protein-1, on the growth of HeLa cells and derived somatic-cell hybrids in nude mice. Mol Carcinog 14: 179-189, 1995. 
46. Braun L, Durst M, Mikumo R, Crowley A and Robinson M: Regulation of growth and gene expression in human papillomavirus-transformed keratinocytes by transforming growth factor-beta: implications for the control of papillomavirus infection. Mol Carcinog 6: 100-111, 1992.

47. Ozbun MA and Meyers C: Transforming growth factor beta1 induces differentiation in human papillomavirus-positive keratinocytes. J Virol 70: 5437-5446, 1996.

48. Borkowski TA, Letterio JJ, Farr AG and Udey MC: A role for endogenous transforming growth factor beta 1 in Langerhans cell biology: the skin of transforming growth factor beta 1 null mice is devoid of epidermal Langerhans cells. J Exp Med 184: 2417-2422, 1996

49. Geissmann F, Prost C, Monnet JP, Dy M, Brousse N and Hermine O: Transforming growth factor beta1, in the presence of granulocyte/macrophage colony-stimulating factor and interleukin 4, induces differentiation of human peripheral blood monocytes into dendritic Langerhans cells. J Exp Med 187: 961-966, 1998.
50. Sato K, Kawasaki H, Nagayama $\mathrm{H}$, et al: TGF-beta 1 reciprocally controls chemotaxis of human peripheral blood monocytederived dendritic cells via chemokine receptors. J Immunol 164: 2285-2295, 2000

51. Strobl H and Knapp W: TGF-beta1 regulation of dendritic cells. Microbes Infect 1: 1283-1290, 1999.

52. Nunez R, Sanchez M, Wild P, Filgueira L and Nunez C: Characterisation of two human dendritic cell-lines that express CD1a, take-up, process and present soluble antigens and induce MLR. Immunol Lett 61: 33-43, 1998.

53. Cole ST and Danos O: Nucleotide sequence and comparative analysis of the human papillomavirus type 18 genome. Phylogeny of papillomaviruses and repeated structure of the E6 and E7 gene products. J Mol Biol 193: 599-608, 1987.

54. Dunzendorfer S, Kaser A, Meierhofer C, Tilg H and Wiedermann CJ: Dendritic cell migration in different micropore filter assays. Immunol Lett 71: 5-11, 2000. 